\title{
Anais do III Simpósio Brasileiro de Investigação de Doenças Neuromusculares
}

\section{"Atualizações e Perspectivas nas Doenças Neuromusculares"}

Data: 05 e 06 de maio de 2017

Local: Escola Paulista de Medicina - Universidade Federal de São Paulo (EPM/UNIFESP). São Paulo-SP, Brasil.

Organizadores: Acary Souza Bulle Oliveira, Fernando Morgadinho dos Santos Coelho, Ricardo Mario Arida, Francis Meire Favero, Ana Lúcia Yaeko da Silva Santos, Cristina dos Santos Cardoso de Sá, Fátima Aparecida Caromano, Luis Fernando Grossklauss, Mariana Callil Voos. 


\section{Objetivo}

III Simpósio Brasileiro de Investigação de Doenças Neuromusculares é destinado a todos os pesquisadores, com o objetivo de apresentar trabalhos inovadores com relação ao tratamento clínico e medicamentoso das Doenças Neuromusculares.

\section{Prêmio "JEAN-MARTIN CHARCOT"}

Serão premiados os três melhores trabalhos desenvolvidos no Curso de Especialização em Intervenção Fisioterapêutica nas Doenças Neuromusculares e Neurologia Clínica.

\section{Prefácio}

Em anos de estudo sobre doenças Neuromusculares têm se pesquisado sobre diagnóstico clínico, laboratorial, imagem e até mesmo avaliações e escalas que possam auxiliar em um diagnóstico precoce e preciso, sempre visando um tratamento adequado na fase inicial dessas doenças.

Sendo a estimativa do tempo, um importante item na expectativa de sobrevida para esses pacientes, se faz necessário a introdução rápida de novas perspectivas de tratamento para doenças neuromusculares, desde tratamentos medicamentosos como terapias gênicas até a reabilitação com tecnologia assistiva.

Apesar de muitas terapias gênicas estarem em fases iniciais, poucas já estão sendo utilizadas na clínica e foram discutidas no III Simpósio de Investigações nas Doenças Neuromusculares. Em contrapartida, a tecnologia assistiva obteve um avanço importante nas pesquisas com comunicação alternativa e aumentativa, também com a realidade virtual, que cada vez mais vem atuando na reabilitação auxiliando os pacientes em suas tarefas na atividade de vida.

Prof. Dra. Francis Meire Favero 


\section{PROGRAMA}

06/05/2017 sábado (Anfiteatro Moacyr E. Alvaro)

08h00 - Entrega do material na Secretaria

08:10h Abertura do evento

Prof. Dr. Acary Souza Bulle Oliveira

Prof. Dra. Francis Meire Favero

Prof. Dr. Fernando Morgadinho Santos Coelho

08:20h Testes e escalas funcionais utilizadas na avaliação de pacientes com Distrofias Musculares

Prof. Dra. Cristina dos Santos Cardoso de Sá - UNIFESP

09:00h Atualizações na avaliação das Medidas da Função Motora - MFM

Prof. Dra. Francis Meire Favero - UNIFESP

09:40h Tecnologia Assistiva em Doenças Neuromusculares

Prof. Viviane da Silva - Consultora Internacional de Recursos Assistivos

\section{0:00h COFFEE BREAK}

10:20h Avaliação sensório-cognitivo-motora em pacientes com Doenças Neuromusculares

Prof. Dra. Mariana Callil Voos - USP

11:00hTratamento respiratório em pacientes com Distrofia Muscular

Prof. Ms. Maria Clariane Berto Hayashi - UNIFESP

11:40h Mesa Redonda: Discussão de avaliação e tratamento para Distrofias Musculares

Chair: Profa. Dra. Francis Meire Fávero

Speakers: Profa. Dra. Cristina dos Santos Cardoso de Sá

Profa. Dra. Mariana Callil Voos

Profa. Ms. Maria Clariane Berto Hayashi

\section{2:00h ALMOÇO}

13:00h Clínica e diagnóstico na distrofia muscular de Duchenne

Prof. Dr. Luis Fernando Grossklauss - UNIFESP

13:50h Novos medicamentos para distrofia muscular de Duchenne

Prof. Dra. Alexandra Prufer de Queiroz Campos Araujo - UFRJ 


\section{5:30h COFFEE BREAK}

15:50h Novas perspectivas no tratamento de Amiotrofia Espinhal Progressiva

Prof. Dr. Edmar Zanoteli - USP

16:30h Discussão de diagnóstico e tratamento para Doenças Neuromusculares

Chair: Prof. Dr. Luis Fernando Grossklauss - UNIFESP

Speakers: Prof. Dra. Alexandra Prufer de Queiroz Campos Araujo UFRJ

Prof. Dr. Edmar Zanoteli - USP

06/05/2017 - sábado

Anf. José Augusto Mochel

08:30h - Desenvolvimento e Análise de Usabilidade do Teste de Acuidade Motora de Pinça Manual em Atividade Gráfica (TAG)

Francisca Francineide Moreira Assalim, Fátima Aparecida Caromano, Cleide Daiana Silva Miguel, Acary Souza Bulle Oliveira

09:00h - Análise Intra-Examinadores do Teste de Acuidade Motora de Pinça Manual em Atividade Gráfica (TAG)

Nathanna Larissa Stefanin, Fátima Aparecida Caromano, Ana Lúcia Yaeko da Silva Santos, Acary Souza Bulle Oliveira

09:30h - Análise Interexaminadores do Teste de Acuidade Motora de Pinça Manual em Atividade Gráfica (TAG)

Ligiane Paula Silveira Lamunier, Fátima Aparecida Caromano, Ana Luiza Console Andreotti, Acary Souza Bulle Oliveira

\section{0:00h COFFEE BREAK}

10:20h - Análise do Desempenho de Mulheres na Faixa de 60 a 69 anos no Teste de Acuidade Motora de Pinça Manual em Atividade Gráfica (TAG)

Mayara de Oliveira Cotrim, Fátima Aparecida Caromano, Luis Fernando Grossklauss, Acary Souza Bulle Oliveira

10:50h - Análise do Desempenho de Mulheres Idosas (70-79 anos) no Teste de Acuidade Motora de Pinça Manual em Atividade Gráfica (TAG)

Vanessa da Silva Nascimento, Fátima Aparecida Caromano, Thiago Henrique da Silva, Acary Souza Bulle Oliveira 
11:20h - Relação entre o controle de tronco e a função de membro superior de paciente com distrofia muscular de Duchenne

Elaine Figueredo de Sousa, Ana Lúcia Yaeko da Silva Santos, Luis Fernando Grossklauss, Acary Souza Bulle Oliveira

\section{2:00h ALMOÇO}

13:00h- Avaliação do controle de tronco e função respiratória em pacientes com distrofia muscular de Duchenne Bruna de Souza Freitas, Cristina Cardoso dos Santos de Sá, Francis Meire Fávero, Acary Souza Bulle Oliveira

13:30h - Correlação entre as Escalas Funcionais em Pacientes com Diagnóstico de Esclerose Lateral Amiotrófica

Carina Vitorino de Medeiros, Francis Meire Fávero, Cristina Cardoso dos Santos de Sá, Acary Souza Bulle Oliveira

14:00h - Análise das escalas cognitivas em pacientes com diagnóstico de Esclerose Lateral Amiotrófica

Luana Cautella da Costa Figo, Francis Meire Fávero, Edmar Zanoteli, Acary Souza Bulle Oliveira

14:30h - Usabilidade da tecnologia eye tracking para comunicação aumentativa.

Letícia Simões Ferreira, Vagner Rogério dos Santos, Abrahão Augusto Juviniano Quadros, Acary Souza Bulle Oliveira

15:00h - Avaliação de aprendizagem motora por meio de tarefa em realidade virtual em indivíduos com distrofia muscular de Duchenne

Karina Silva de Oliveira, Talita Dias, Fátima Aparecida Caromano, Acary Souza Bulle Oliveira

\section{5:30h COFFE BREAK}

15:50h - Instrumentos de Avaliação da Dor em indivíduos com distrofia muscular de Duchenne - uma revisão de literatura Nelma Silva dos Santos, Thais Massetti, Francis Meire Favero, Acary Souza Bulle Oliveira

06/05/2017 - sábado

Anf. Ida Vitória Paulini

08:30h - Efeitos na terapia por Contensão Induzida modificada em pacientes com Acidente Vascular Encefálico 
Francisca Antônia Almeida de Carvalho Guerreiro, Francis Meire Favero, Luis Fernando Grossklauss, Fernando Morgadinho Santos Coelho

09:00h - Análise do Perfil de Processamento Sensorial de Crianças com Transtorno do Espectro Autista e seus Pais

Raquel Kaori Nagai, Ana Luiza Console Andreotti, Mariana Callil Voos, Fernando Morgadinho Santos Coelho

09:30h - Análise do Desempenho Funcional de Pacientes Hemiparéticos após Aplicação de Bloqueio Químico

Marília Luna Pereira, Fernando Morgadinho Santos Coelho, Rafael Eras Garcia, Mariana Callil Voos

\section{0:00h COFFEE BREAK}

10:30h - Perfil e Desenvolvimento de Criança com Síndrome de Pallister Killian em Tratamento Fisioterapêutico - Relato de Caso

Ana Paula Bernardino, Mariana D'Angelo Cauchioli, Fabricio Ferreira de Oliveira, Fernando Morgadinho Santos Coelho

11:00h - Neuromodulação e Novas Perspectivas para Reabilitação

Poliana Tange Santos, Thais Tavares Terranova, Fabricio Ferreira de Oliveira, Fernando Morgadinho Santos Coelho

11:30h - Implementação do Cuidado de Enfermagem ao cliente acometido com Trauma Raquimedular na Fase Aguda e Proposta de um Protocolo.

Gabriela Ramos Gomes dos Santos, Ana Paula Guarnieri, Élica Fernandes, Fernando Morgadinho Santos Coelho

\section{2:00h ALMOÇO}

13:30h - Protocolo para Avaliação Interdisciplinar da Diadococinesia

Jessica Talita da Cruz Albuquerque, Mariana Callil Voos, Christiane Brunini, Fernando Morgadinho Santos Coelho

14:00h - Aplicação da Terapia de Contensão Induzida (TCI) adaptada no Ambiente Virtual em Pacientes com Acidente Vascular Cerebral

Willian Severino da Silva, Talita Dias da Silva, Cristina dos Santos Cardoso de Sá, Fernando Morgadinho Santos Coelho 


\section{TESTES E ESCALAS FUNCIONAIS UTILIZADAS NA AVALIAÇÃO DE PACIENTES COM DISTROFIA MUSCULAR}

\section{FUNCTIONAL TESTS AND SCALES USED IN THE EVALUATION OF PATIENTS WITH MUSCULAR DYSTROPHY}

Cristina dos Santos Cardoso de Sá

Profa. Dra. Departamento de Ciências do Movimento Humano Universidade Federal de São Paulo - Campus Baixada Santista

\section{RESUMO}

As distrofias musculares (DM) são um grupo de desordens heterogêneas geneticamente determinadas, identificadas clinicamente por grande variabilidade do fenótipo e de gravidade e caracterizadas por fraqueza muscular. A maioria das DM compartilha a mesma característica patológica. Conforme o curso da doença, o tecido muscular sofre lesões que acarreta na formação de fibrose e posteriormente o tecido muscular é substituído por gordura. No entanto, o mecanismo de evolução e a velocidade em que ele ocorre em cada uma das formas específicas pode variar. A degeneração progressiva da musculatura esquelética acarreta a fraqueza e atrofia muscular e na instalação de contraturas e deformidades dos músculos do esqueleto axial, do cíngulo escapular e dos membros superiores (MMSS) e membros inferiores (MMII) são características inerentes de todo o grupo de DM. Dessa forma o acompanhamento periódico da função motora nas DM permite estabelecer a evolução clínica dos parâmetros e as repercussões funcionais. Há grandes esforços para identificar medidas de resultados nas DM. Uma série dessas medidas, incluindo o desenvolvimento de escalas da avaliação funcional e medidas de tempo de atividade estão sendo validadas, com análises de confiabilidade. Podemos citar as seguintes escalas: Egen Klassifikation (EK); North Star Ambulatory Assessment (NSAA); Functional Evaluation Scale for Duchenne Muscular Dystrophy (FESDMD); Function Testing Manual Jebsen Taylor (TJT); Performance of Upper Limb (PUL).

Palavras-chave. Distrofia Muscular, Avaliação, Atividade Motora 


\section{ABSTRACT}

The muscular dystrophies (MD) are a group of genetically determined disorders heterogeneous, identified clinically by great variety of phenotypes and severity and characterized by muscle weakness. Most MD share the same pathological feature. As the disease progresses, muscle tissue suffers injuries that may cause fibrosis formation and subsequently the muscle tissue is replaced by fat. However, the mechanism of evolution, and the speed at which it occurs in each of the specific forms may vary. The progressive degeneration of skeletal muscle causes the muscle weakness and atrophy and contractures and deformities installation of the axial skeleton muscles, shoulder girdle and upper limb (UL) and lower limb (LL) are inherent characteristics of all the MD group. Thus, the periodic monitoring of the motor function in the MD allows to establish the clinical evolution of the parameters and the functional repercussions. There are great efforts to identify outcome measures in MD. A number of these measures, including the development of functional assessment scales and uptime measures, are being validated with reliability analyzes. We can cite the following scales: Egen Klassifikation (EK); North Star Ambulatory Assessment (NSAA); Functional Evaluation Scale for Duchenne Muscular Dystrophy (FES-DMD); Function Testing Manual Jebsen Taylor (TJT); Performance of Upper Limb (PUL).

Keywords. Muscular Dystrophy, Evaluation, Motor activity 


\section{ATUALIZAÇÕES NA AVALIAÇÃO DAS MEDIDAS \\ DA FUNÇÃO MOTORA - MFM}

\section{UPDATES IN EVALUATING THE MEASURES \\ MOTOR FUNCTION - MFM}

Francis Meire Fávero

Professora Afiliada da Universidade Federal de São Paulo - UNIFESP

Professora da Universidade Ibirapuera - UNIB

\section{RESUMO}

A Medida da Função Motora (MFM) visa mensurar as habilidades funcionais, com o objetivo de avaliar e acompanhar de forma longitudinal da progressão das doenças neurodegenerativas. Para realizar o estudo de atualização da escala Medida da Função Motora (MFM), foram selecionados no MeSH e DeCS, descritores para estratégia de busca e encontrado "Muscular Dystrophy, Duchenne" and "Motor" and "function" and "Measure", esses foram utilizados como fonte de busca nas bases eletrônicas Medline/PubMed e BVS (Virtual Library in Health), SCIELO (Scientific Eletronic Library On Line) e Plataforma Pedro (Physiotherapy Evidence Database). Nesta revisão foram encontrados onze artigos que apresentavam dados a Medida da Função Motora (MFM) dos pacientes com Distrofia Muscular de Duchenne (DMD), essa escala está correlacionada nesses artigos com outras medidas de avaliação para a função motora, a força muscular, a amplitude de movimento, a marcha, a qualidade de vida, e outros instrumentos utilizados para avaliar a força como dinamômetros e realizar exercícios como o ciclo ergômetro de 6 minutos. De acordo, com esses estudos pode-se inferir que a MFM é uma escala que avalia a função motora, em pacientes com DMD deambulantes e cadeirantes, e que, através de sua análise é possível obter dados que acompanha a evolução da doença.

Palavras-Chave. Distrofia Muscular de Duchenne, Função, Motor, Medida, avaliação, escala 


\section{ABSTRACT}

The Motor Function Measure (MFM) aims to measure the functional abilities, with the objective of evaluating and longitudinally accompanying the progression of neurodegenerative diseases. In order to perform the study of the Motor Function Measurement (MFM), MeSH and DeCS search engine descriptors were searched for and found "Muscular Dystrophy, Duchenne" and "Motor" and "function" and "Measure". Were used as a search source in the electronic databases Medline / PubMed and Virtual Library in Health (VHL), Scientific Eletronic Library On Line and Pedro Platform (Physiotherapy Evidence Database). In this review eleven articles were found that presented data to Motor Function Measurement (MFM) of patients with Duchenne Muscular Dystrophy (DMD), this scale is correlated in these articles with other assessment measures for motor function, muscle strength, range of motion, gait, quality of life, and other instruments used to assess strength as dynamometers and perform exercises such as the 6-minute cycle ergometer. According to these studies, it can be inferred that MFM is a scale that assesses motor function in patients with ambulatory and wheelchairbound DMD, and that through their analysis it is possible to obtain data that accompany the evolution of the disease.

Keywords: Muscular Dystrophy, Duchenne, function, motor, measure, evaluation, scale 


\section{TECNOLOGIA ASSISTIVA E COMUNICAÇÃO ALTERNATIVA}

Viviane da Silva

Fisioterapeuta, Especialista em Intervenção Fisioterapêutica nas Doenças Neuromusculares

\section{RESUMO}

Os profissionais de reabilitação orientam seus pacientes ao uso da tecnologia Assistiva para comunicação Ampliada e Alternativa (CAA). Assim, este artigo objetiva oferecer uma base conceitual de Tecnologia Assistiva (TA) e dos recursos de comunicação alternativa. Foi utilizada a pesquisa bibliográfica com o objetivo de definir a Tecnologia Assistiva e quais as possibilidades de recursos de Comunicação para as pessoas com doenças neurológicas. As doenças neurológicas, compreendem um grande problema de saúde da sociedade moderna, em consequência do crescente número de pessoas acometidas, também, devido à inexistência de cura para estas patologias crônicas e progressivas, vemos que em decorrência do aumento da expectativa de vida da população, resultando em uma maior prevalência de neurodegenerativas, como Alzheimer, Parkinson, Huntington e esclerose múltipla, esclerose Lateral Amiotrófica (ELA), mas, temos doenças raras e Paralisias Cerebrais (PC) que acometem crianças em todo o mundo, também aos acidentes vasculares cerebrais (AVC), neoplasias, epilepsia, entre outras, bem como outras diretamente ligadas ao envelhecimento, de origem genética ou traumática. As tecnologias assistivas, são um grande arsenal terapêutico e agem de forma a ampliar a mobilidade, comunicação e habilidades de aprendizado estratégias e práticas concebidas e aplicadas para minorar os problemas encontrados pelos indivíduos com deficiências" (Cook e Hussey - Assistive Technologies: Principles and Practices - Mosby - Year Book, Inc., 1995). A comunicação alternativa (CA) é utilizada por pessoas sem fala ou sem escrita funcional ou em defasagem entre sua necessidade comunicativa e sua habilidade de falar e/ou escrever. Crianças e 
adultos são beneficiados pelo seu uso, seja via prancha de comunicação de alta e/ou de baixa tecnologia no ambiente familiar, social e escolar. O Uso precoce destes recursos auxilia no desenvolvimento infantil além de não limitar a produção da aquisição da fala, favorece a sua organização, sendo a participação ativa da família fundamental para o sucesso terapêutico (Cesa, 2015). Com o objetivo de ampliar ainda mais o repertório comunicativo que envolve habilidades de expressão e compreensão, são organizados e construídos auxílios externos como cartões de comunicação, pranchas de comunicação, pranchas alfabéticas e de palavras, vocalizadores ou o próprio computador que, por meio de software específico, pode tornar-se uma ferramenta poderosa de voz e comunicação. Além do desenvolvimento de novas tecnologias como o "Eye Tracking" que são ferramentas hibridas (software e hardware) que possuem sistema em infravermelho que com câmera embutida, identificam e calibram o movimento dos olhos permitindo que a pessoa se comunique inteiramente com o movimento dos olhos. Para uma melhor adequação dos recursos de comunicação de cada pessoa são construídos de forma totalmente personalizada e levam em consideração várias características que atendem às necessidades deste usuário (Berst, 2005). A inclusão destes temas em simpósios e congressos tem sido muito esclarecedora, trazendo a luz maiores possibilidades de ferramentas de atuação. O Desenvolvimento tecnológico traz possibilidades crescentes e de alternativas factíveis, desde placas com alfabetos que podem ser feitos a mão e são classificados como baixa tecnologia a alta tecnologia como o Eye Tracking, que permitem comunicações apenas com o movimento dos olhos, permitindo que pessoas com alto comprometimento deem voz a sua vida.

\section{REFERÊNCIAS}

1.ADA - American with Disabilities ACT 1994. Disponível em: https://www.resna.org/ 
2.BRASIL. SDHPR - Secretaria Nacional de Promoção dos Direitos da Pessoa com Deficiência - SNPD. 2009. Disponível em: https://www.pessoacomdeficiencia.gov.br/app/publicacoes/tecnologiaassistiva

3.BRASIL. SDHPR - Secretaria Nacional de Promoção dos Direitos da Pessoa com Deficiência - SNPD. 2012 Disponível em: https://www.pessoacomdeficiencia.gov.br/app/

4.Bersch R. Introdução à Tecnologia Assistiva. 2005. Disponível http://www.assistiva.com.br/Introducao Tecnologia Assistiva.pdf

5.Brasil, 2017 - Cresce a Inclusão de deficientes em sala comum Disponível em: http://www.brasil.gov.br/noticias/educacao-eciencia/2011/04/cresce-inclusao-de-deficientes-em-sala-comum

6.Brasil. Subsecretaria Nacional de Promoção dos Direitos da Pessoa com Deficiência. Comitê de Ajudas Técnicas. Tecnologia Assistiva. Brasília: CORDE, 2009. 138 p.

7.Cesa CC, Mota HB. Comunicação aumentativa e alternativa: panorama dos periódicos brasileiros. Rev CEFAC 2015;17:264-9.

8.Cook, Hussey. Assistive Tecnologies: Principles and Pratice. Missouri: Mosby - Year Book, 1995.

9.Fachinetti TA, Urel RCC. A Tecnologia Assistiva como facilitadora no processo de inclusão: Das Políticas Públicas a Literatura. Rev Polít Gestão Edu 2017;21:1588-97.

10.Galvão Filho TA. Conceituação e estudo de normas. In: BRASIL, Tecnologia Assistiva. Brasília: CAT/SEDH/PR, 2009, p.13-39.

11.IDEA, 2004 - Ohio AT Network Assistive Technology Resource Manual page 42 February 2008 Disponivel em : https://assistedtechnology.weebly.com/uploads/3/4/1/9/3419723/at guide. pdf acesso 15/05/2019

12. Manzini EJ. Tecnologia assistiva para educação: recursos pedagógicos adaptados. In: Ensaios pedagógicos: construindo escolas inclusivas. Brasília: SEESP/MEC, 2005, p.82-6.

13. Radabaugh MP. NIDRR's Long Range Plan - Technology for Access and Function Research Section Two: NIDDR Research Agenda Chapter 5: technology for access and function.

14. Varela RCB, Oliver FC. A utilização de Tecnologia Assistiva na vida cotidiana de crianças com deficiência. Ciênc Saúde Col 2013;18. 


\section{AVALIAÇÃO SENSÓRIO-COGNITIVO-MOTORA EM PACIENTES COM DOENÇAS NEUROMUSCULARES}

\section{SENSORY-COGNITIVE-MOTOR EVALUATION IN PATIENTS WITH NEUROMUSCULAR DISEASES}

Mariana Callil Voos

Departamento de Fisioterapia, Fonoaudiologia e Terapia Ocupacional da Faculdade de Medicina da USP

\section{RESUMO}

Este estudo teve como objetivo investigar o desempenho em tarefas de pareamento em crianças com Atrofia Muscular Espinal Tipo I (SMA-I) e a relação entre esse desempenho e função motora, independência funcional e qualidade de vida. No grupo com SMA-I havia 12 crianças (idade: 6,0 2,3 anos; 9 meninos e 3 meninas) e no grupo controle as 12 crianças foram pareadas por sexo e idade $(6,2 \pm 2,6$ anos). Todos realizaram quatro tarefas de pareamento com figuras, números e letras. O rastreador ocular detectou os movimentos oculares. As crianças do grupo SMA-I foram avaliadas com a escala CHOP INTEND, o Inventário Pediátrico de Avaliação de Incapacidade e o Inventário Pediátrico de Qualidade de Vida. A análise de variância mostrou que as crianças SMA-I apresentaram menor porcentagem de respostas corretas e maior tempo de desempenho em relação ao grupo controle $(p<0,05)$. A pontuação no Inventário Pediátrico de Avaliação de Incapacidade (domínio da função social) foi correlacionada com a porcentagem de respostas corretas nas tarefas de correspondência de pares de figuras $(r=0,81$; $p=0,001)$ e de pares de figuras com suas cores respectivas $(r=0,66$; $p=0,020)$. O desempenho de crianças com SMA-I foi pior do que o desempenho de crianças do grupo controle. Houve correlação entre a capacidade de fazer o pareamento e a função social. A interação restrita com o ambiente, devido à paralisia grave e pouca ou nenhuma comunicação verbal, está associada a dificuldades cognitivas em crianças com SMA-I. O rastreador ocular foi útil na 
avaliação cognitiva de crianças com SMA-I, que responderam aos testes cognitivos com movimentos oculares.

Palavras-chave. Cognição; atrofia muscular espinhal; percepção visual

\section{ABSTRACT}

This study aimed to investigate the performance on pair-matching tasks in children with Spinal Muscular Atrophy type I (SMA-I) and the relationship between this performance and motor function, functional independence and quality of life. SMA-I ( $n=12 ; 6.0 \pm 2.3$ yrs; 9 boys, 3 girls) and control sex-, age-matched children ( $n=12 ; 6.2 \pm 2.6 \mathrm{yrs}$ ) performed four pair-matching figure, number and letter tasks. The eye tracker detected eye movements. SMA-I children were assessed with CHOP INTEND, Pediatric Evaluation of Disability Inventory, and Pediatric Quality of Life Inventory. Analysis of variance showed that SMA-I children had a lower percentage of correct answers and longer timed performance compared to controls $(p<0.05)$. Pediatric Evaluation of Disability Inventory score (social function domain) was correlated to the percentage of correct answers on the pair-matching tasks on task $1(r=0.81 ; p=0.001)$ and task $2(r=0.66 ; p=0.020)$. Pair-matching performance of SMA-I children was poorer than the performance of control children. There was a relationship between pair-matching performance and social function. The restricted interaction with the environment, due to severe paralysis and poor verbal communication, is associated with cognitive difficulties in SMAI children. The eye tracker was helpful in cognitive assessment of SMA-I children, who responded to the cognitive tests with eye movements.

Keywords. Cognition; Spinal muscular atrophy; Visual perception 


\title{
TRATAMENTO RESPIRATÓRIO EM PACIENTES COM DISTROFIA MUSCULAR
}

\author{
RESPIRATORY TREATMENT IN PATIENTS WITH MUSCULAR \\ DYSTROPHY
}

Maria Clariane Berto Hayashi

Professora do curso de especialização em Doenças Neuromusculares da UNIFESP.

\section{RESUMO}

Os pacientes com Distrofia Muscular evoluem com fraqueza muscular inspiratória, expiratória e dos músculos da via aérea superior, sendo que este último é acometido somente por alguns tipos de distrofia. A disfunção ventilatória está relacionada principalmente com a fraqueza muscular inspiratória, a disfunção da tosse com a fraqueza muscular inspiratória e expiratória e fraqueza muscular bulbar (função da glote) e a disfunção da via aérea superior relaciona-se com a fraqueza muscular bulbar. Manter a mecânica respiratória em bom funcionamento é muito importante para esses pacientes. Para que isso ocorra é necessário higiene brônquica, expansão pulmonar e mobilidade da caixa torácica. Essas três ações corroboram para o aumento da ventilação alveolar e previnem a insuficiência respiratória. Para a higiene brônquica podemos realizar 0 Air-Stacking associado com a prensa abdominal ou torácica e desta forma promover tosse mais eficaz para o paciente. Pacientes com PFT (Pico de Fluxo de Tosse) <270L/min, tem indicação de assistência mecânica da tosse com o Cough Assist. O Cough Assist é um equipamento que realiza a insuflação e exsuflação mecânica, ou seja, aplica uma pressão positiva (insuflação) seguida de uma mudança rápida para a pressão negativa (exsuflação), simulando a tosse. Pode ser utilizado em crianças e adultos. A mobilidade da caixa torácica decorre da expansão pulmonar, para isso é necessário atingir a CIM (Capacidade de Insuflação Máxima). A CIM pode ser obtida de várias maneiras: através do ressuscitador manual, também conhecido como "ambu", respiração glossofaríngea, ventilador mecânico de 
suporte a vida configurado do modo a volume e Cough Assist com a pressão negativa desligada. Todos esses promovem o air-stacking (empilhamento de ar). Os pacientes com distrofia muscular evoluem em momentos diferentes para a ventilação não invasiva. A indicação segundo o Consensus Conference, publicado na Chest 1999, ocorre quando há sintomas de fadiga, dispneia, cefaleia matinal + uma alteração fisiológica: $\mathrm{PaCO} 2$ vigília $>45 \mathrm{mmHg}$, SaO2 noturna $\leq 88 \%$ por 5 min contínuos, $\mathrm{CVF}<50 \%$, Pressão inspiratória máxima $<60 \mathrm{~cm}$ $\mathrm{H}_{2} \mathrm{O}$ ). A ventilação deve ser iniciada no período noturno e conforme a evolução da doença inicia-se no período diurno também. Manter um modo ventilatório que garante uma frequência de backup é essencial para esses pacientes, assim como ter um equipamento que permita ventilação a volume. Para o sucesso da ventilação, é importante ter diferentes tipos de máscaras, pois um nariz é diferente de outro. Hoje as indústrias disponibilizam muitos modelos, como a máscara nasal de mínimo contato também conhecida como pillow, nasal, oronasal e facial total e a peça bucal, sendo esta última utilizada somente em ventiladores de suporte a vida no modo a volume. Segundo o Jornal Breathe, 2013, os pacientes com necessidade de ventilação mecânica maior que $16 \mathrm{hs} /$ dia necessitam de ventilador de suporte a vida, já os pacientes com ventilação menor que $16 \mathrm{~h} /$ dia necessitam de suporte respiratório como exemplo temos os bileveis.

Palavras-Chave. Distrofia Muscular de Duchenne, Função, fraqueza, fadiga, respiratória.

\section{ABSTRACT}

Patients with Muscular Dystrophy develop with inspiratory, expiratory muscle weakness and upper airway muscles, the latter being affected only by some types of dystrophy. Ventilatory dysfunction is mainly related to inspiratory muscle weakness, cough dysfunction with inspiratory and expiratory muscle weakness, and bulbar muscle weakness (glottal function), and upper airway dysfunction is related to bulbar muscle weakness. Keeping respiratory mechanics in good 
working order is very important for these patients. For this to occur, bronchial hygiene, lung expansion, and chest cavity mobility are necessary. These three actions corroborate the increase in alveolar ventilation and prevent respiratory failure. For bronchial hygiene, we can perform the Air-Stacking associated with the abdominal or thoracic press and in this way to promote more effective cough for the patient. Patients with PFT (Cough Flow Peak) $<270$ L/min, have indication of mechanical cough assistance with Cough Assist. The Cough Assist is an equipment that performs the insufflation and mechanical exsuflation, that is, it applies a positive pressure (insufflation) followed by a rapid change to the negative pressure (exsuflation), simulating the cough. Can be used in children and adults. The mobility of the chest cavity is due to pulmonary expansion, for this it is necessary to reach the MIC (Maximum Intubation Capacity). MIC can be obtained in a number of ways: through the manual resuscitator, also known as ambu, glossopharyngeal breathing, mechanical ventilator for life support set to volume mode and Cough Assist with negative pressure off. All of these promote air-stacking. Patients with muscular dystrophy evolve at different times for noninvasive ventilation. The indication according to the Consensus Conference, published in Chest 1999, occurs when there are symptoms of fatigue, dyspnea, morning headache $+a$ physiological alteration: $\mathrm{PaCO} 2$ wakefulness $>45 \mathrm{mmHg}$, night $\mathrm{SaO} 2<88 \%$ for 5 continuous minutes, $\mathrm{FVC}<50 \%$, Pressure Inspiratory maximum $<60 \mathrm{~cm} \mathrm{H2O}$ ). Ventilation should be started at nighttime and as the disease progresses it starts in the daytime period as well. Maintaining a ventilatory mode that ensures a backup frequency is essential for these patients, as well as having equipment that allows volume ventilation. For successful ventilation, it is important to have different types of masks because one nose is different from another. Today the industries offer many models, such as the nasal mask of minimum contact also known as pillow, nasal, oronasal and total facial and the mouthpiece, the latter being used 
only in ventilators supporting life in volume mode. According to the Breathe Journal, 2013, patients requiring mechanical ventilation longer than $16 \mathrm{~h} /$ day require a life support ventilator, since patients with ventilation less than $16 \mathrm{~h} /$ day need respiratory support as an example we have the Bilevel.

Keywords. Muscular Dystrophy, Duchenne, function, weakness, fatigue, respiratory 


\section{CLÍNICA E TRATAMENTO DA DISTROFIA MUSCULAR DE DUCHENNE}

\section{CLINICAL AND TREATMENT OF DUCHENNE MUSCULAR DYSTROPHY}

Luis Fernando Grossklauss

Médico Neuropediatra Setor de investigação de Doenças

Neuromuscular da UNIFESP

\section{RESUMO}

A Distrofia muscular de Duchenne é causada pela ausência de distrofina nos músculos é uma doença ligada o cromossomo X. Os meninos afetados evoluem com perda da marcha aos 10 anos com óbito por volta de 25 a 30anos. O Protocolo de atendimento dos pacientes inclui: Corticoterapia com predinisolona $0,75 \mathrm{mg} / \mathrm{kg} / \mathrm{dia}$ ou deflazacort $0,9 \mathrm{mg} / \mathrm{kg} / \mathrm{dia}$, é solicitado densitometria óssea anualmente e indicado bifosfonados quando há perda de massa óssea. Raio $x$ de coluna anual se escoliose estiver ente $15^{\circ}$ e $20^{\circ}$, semestralmente se maior que $20^{\circ} \mathrm{e}$ a cirurgia de artrodes de coluna se escoliose maior que $30^{\circ}$ e obliquidade pélvica maior que $15^{\circ}$. $\mathrm{O}$ manejo respiratório é conforme a Portaria 370 de 4/7/2008 sendo a indicação do bilevel pelo menos 1 sintoma clinico como dispneia, cefaleia matinal, ronco, apneia, sonolência diurna ou pneumonia de repetição e pelo menos 1 sintoma numérico como CVF menor que $50 \%$, ou na polissonografia: IAH maior que $15 \mathrm{ev} / \mathrm{hora}$ SatO 2 menor que $88 \%$ por 5 minutos ou $\mathrm{PaCo} 2$ maior que $45 \mathrm{mmhg}$ por 5 minutos. Manejo cardíaco constitui em Ecocardiograma a cada 2 anos até 10 anos de idade após anualmente até alterar; os problemas cardíacos mais frequentes são miocardiopatia dilatada tratamento com ieca, beta bloqueadores e diuréticos e arritmias. Ainda evoluem com disfagia sendo o desfecho a gastrostomia e obstipação intestinal necessitando de medicação a base de macrogol e suplementação de fibras deve ser evitado piorando o quadro pois os pacientes têm baixa ingesta de água. 
Palavras-Chaves. distrofia muscular de Duchenne, protocolo, tratamento, fraqueza muscular

\section{ABSTRACT}

Duchenne muscular dystrophy is caused by the absence of dystrophin in the muscles is a disease linked to the $X$ chromosome. The affected boys evolve with loss of gait at age 10 with death around 25 to 30 years. The Patient Care Protocol includes: steroid therapy with prednisolone $0.75 \mathrm{mg} / \mathrm{kg} /$ day or deflazacort $0.9 \mathrm{mg} / \mathrm{kg} / \mathrm{day}$, bone densitometry annually and bisphosphonates when loss of bone mass. Spine radiography annual if scoliosis is between $15^{\circ}$ and $20^{\circ}$, twice a year if greater than $20^{\circ}$ and spinal arthrodesis when greater than $30^{\circ}$ and pelvic obliquity greater than $15^{\circ}$. Respiratory management complies in accordance (in Brazil) by Act 370 of $4 / 7 / 2008$ and the indication of the bilevel is at least 1 clinical symptom such as dyspnea, matinal headache, snoring, apnea, daytime somnolence or repetitived pneumonia and at least 1 numerical symptom as FVC less than $50 \%$, or in polysomnography: apneia index greater than $15 \mathrm{ev} /$ hour, Saturation $\mathrm{O} 2$ less than $88 \%$ for 5 minutes or $\mathrm{PaCo} 2$ greater than $45 \mathrm{mmhg}$ for 5 minutes. Cardiac management constitutes in Echocardiogram every 2 years until 10 years of age after annually until alter; The most frequent cardiac problems are dilated cardiomyopathy treatment with enalapril, carvedilol and diuretics and arrhythmias. The boys with dysphagia the end point is gastrostomy and the intestinal constipation need macrogol therefore fiber supplementation should be avoided at risk worsening the condition because patients drinks low water intake.

Keywords. Muscular Dystrophy, Duchenne, treatment, protocol, Muscle Weakness 


\section{NOVOS MEDICAMENTOS PARA DISTROFIA MUSCULAR DE DUCHENNE}

NEWS MEDICATIONS FOR DUCHENNE MUSCULAR DYSTROPHY

Alexandra Prufer de Queiroz Campos Araujo

Professora Associada de Neuropediatria, Universidade Federal do Rio de Janeiro

\section{RESUMO}

Avanços significativos na compreensão e no manejo da Distrofia Muscular de Duchenne (DMD) ocorreram desde a publicação de diretrizes internacionais para o cuidado destes pacientes em 2010. Nosso objetivo foi elaborar uma revisão dos mecanismos patogênicos que permitiram a elaboração de estratégias de tratamentos medicamentosos específicos ou inespecíficos. Abordamos as etapas no desenvolvimento de novas terapias e finalizamos com as novas perspectivas de tratamentos medicamentosos para DMD.

Palavras-chave. Distrofia Muscular de Duchenne, terapêutica

\section{ABSTRACT}

Significant advances in the understanding and management of Duchenne Muscular Dystrophy (DMD) have occurred since the publication of International guidelines for DMD care in 2010. Our objective was to provide review on pathogenic mechanisms that provided the targets for specifc or inespecific drug therapies. The steps for a development of new therapies followed and the new drug treatment perspectives for DMD were presented.

Keywords. Muscular Dystrophy, Duchenne, Therapeutic.

\section{Bases para desenvolvimento de novos tratamentos}

No século XIX, a partir da descrição clínica dos casos de meninos com quadro de fraqueza muscular progressiva, hipertrofia de panturrilha e se levantar do solo característico, seguido do reconhecimento dos 
aspectos neurofisiológicos e histopatológicos, a distrofia muscular de Duchenne foi reconhecida com entidade nosológica.

Embora avanços nos cuidados básicos, os voltados para as complicações respiratórias e o uso da corticoterapia propiciaram melhor expectativa de vida, apenas depois do conhecimento mais detalhado das etapas fisiopatológicas envolvidas na doença abriram o caminho para as novas perspectivas terapêuticas.

Desta forma o reconhecimento do gene, das mutações associadas com a doença, a função da proteína por ele produzido e que se encontra deficiente na DMD, assim como o desequilíbrio causado pela degeneração das fibras musculares e insuficiente capacidade de regeneração, culminaram com as ideias de intervenção terapêuticas desenvolvidas a partir de então.

Novas propostas

- Correção da leitura com produção de distrofina funcional

- Reposição de minigene de distrofina

- Redução de fibrose, do processo inflamatório, utrofina, inibição de miostatina (aumentar massa muscular), terapia celular

- Edição do material genético (CRISP/Cas9)

\section{Ensaios clínicos}

O desenvolvimento de novas terapias demanda tempo e método. Este processo envolve duas fases de pesquisas: a pré-clínica e a clínica. $\mathrm{Na}$ primeira são feitos os testes do novo tratamento em células ou tecido mantido em cultura, e em modelos animais. As fases clínicas são aquelas que se seguem, quando os estudos pré-clínicos são favoráveis, envolvem seres humanos e são subdivididas em 4 fases. A fase 1 é a que busca conhecer a segurança da nova terapia, pode ser feita com indivíduos sadios ou com a doença. A fase 2 , por meio de estudos farmacocinéticos, objetiva definição de dose e via de administração. A fase 3 é a dos ensaios clínicos controlados randomizados duplo cego, quando se estudo a eficácia da terapia, 
comparada ao placebo. Se após estas 3 fases se conseguem obter provas de segurança e eficácia o novo tratamento pode ser submetido aos órgãos regulatórios para avaliação de sua comercialização. Se aprovado são feitos então os estudos de fase 4, ensaios abertos para continuar o aprendizado sore a nova terapia.

$\mathrm{Na}$ página eletrônica clinicaltrials.gov encontram-se listados os estudos clínicos, abertos para recrutamento ou não.

Tabela 1. Estudos clínicos de fase 1.

\begin{tabular}{|l|l|l|}
\hline Nome & Alvo & Centros \\
\hline $\begin{array}{l}\text { DS } 5141 \\
\text { (oligonucleotideo SC) }\end{array}$ & Gene - salto do exon 45 & Japão \\
\hline $\begin{array}{l}\text { rAAVrh74.MCK.Micro- } \\
\text { Dystrophin (IM) }\end{array}$ & $\begin{array}{l}\text { Transferência de micro } \\
\text { gene }\end{array}$ & US \\
\hline Rimeporide (VO) & Bloqueio bomba prótons & $\begin{array}{l}\text { França, Itália, Espanha, } \\
\text { Reino Unido }\end{array}$ \\
\hline Epicatechin (VO) & Antioxidante & US \\
\hline $\begin{array}{l}\text { Transplante de mioblastos } \\
\text { (IM) }\end{array}$ & Tecido muscular & Canadá \\
\hline Tamoxifeno & Antifibrótico & \\
\hline
\end{tabular}

Tabela 2. Estudos clínicos de fase 2.

\begin{tabular}{|l|l|l|}
\hline Nome & Alvo & Centros \\
\hline $\begin{array}{l}\text { NS-065/NCP-01 } \\
\text { (Oligonucleotideo EV) }\end{array}$ & Gene - Salto de exon 53 & US, Canadá \\
\hline Eteplirsen (EV) & Gene - Salto de exon 51 & US \\
\hline BMS 986089 (SC) & Anti miostatina & $\begin{array}{l}\text { US, Argentina, Austrália, } \\
\text { Canadá, Bélgica, França, } \\
\text { Alemanha, Itália, Holanda, } \\
\text { Espanha, Suécia, Reino }\end{array}$ \\
\hline
\end{tabular}




\begin{tabular}{|l|l|l|}
\hline & & Unido, Japão \\
\hline Vamorolone (VO) & Novo esteróide & $\begin{array}{l}\text { US, Canadá, Austrália, } \\
\text { Israel, Japão, Reino Unido, } \\
\text { Suécia }\end{array}$ \\
\hline $\begin{array}{l}\text { Pamrevlumab (EV) } \\
\text { PF }\end{array}$ & $\begin{array}{l}\text { US } \\
\text { (domagrozumab EV) }\end{array}$ & $\begin{array}{l}\text { Anticorpo monoclonal: } \\
\text { fator } \\
\text { crescimento de } \\
\text { tecido } \\
\text { conjuntivo } \\
\text { miostatina }\end{array}$ \\
\hline
\end{tabular}

Tabela 3. Estudos clínicos de fase 3.

\begin{tabular}{|l|l|l|}
\hline Nome & Alvo & Centros \\
\hline $\begin{array}{l}\text { SRP-4045 (EV) } \\
\text { SRP } 4053(\mathrm{EV})\end{array}$ & $\begin{array}{l}\text { Gene } \\
\text { - Salto de exon } \mathbf{4 5} \\
\text { - Salto de exon 53 }\end{array}$ & $\begin{array}{l}\text { US, Bélgica, Canada', } \\
\text { França, Alemanha, Itália, } \\
\text { Holanda, Espanha, Suécia, } \\
\text { Reino Unido }\end{array}$ \\
\hline Givinostat & $\begin{array}{l}\text { Antiinflamatório, inibidor } \\
\text { de HDAC }\end{array}$ & $\begin{array}{l}\text { US, Canada, Bélgica, } \\
\text { França, Alemanha, Itália, } \\
\text { Holanda, Espanha, Reino } \\
\text { Unido }\end{array}$ \\
\hline Idebenona (VO) & Mitocôndria - antioxidante & $\begin{array}{l}\text { US, Áustria, Bélgica, } \\
\text { França Alemanha, Israel, } \\
\text { Itália, Holanda, Espanha, } \\
\text { Suécia, Suíça, Reino Unido }\end{array}$ \\
\hline
\end{tabular}

\section{Terapias específicas:}

- Terapia para deleções

Para abordar casos de meninos com DMD que apresentam deleções de exons, que interrompem a leitura do RNA e consequentemente a produção de distrofina, concebeu-se substâncias que se ligam aos oligonucleotídeos que permitem o salto de exon adjacente à deleção e desta forma recompor a possibilidade de leitura. O Eteplirsen é um novo medicamento recentemente aprovado nos Estados Unidos que utiliza este mecanismo.

- Terapia para código de parada prematura 
Uma das alterações genéticas que leva a incapacidade de produção de distrofina são mutações de ponto que transformam uma trinca de nucleotídeos codificadores de aminoácido em uma trinca que contém um código de parada prematura. Neste caso o exemplo é o medicamento Ataluren que foi aprovado pela agência Europeia de medicamentos. Trata-se de uma substância que "força" o ribossomo a passar pelo código de parada prematuro mantendo a produção da distrofina.

- Terapia gênica independente da mutação

A possibilidade de inserir um microgene de distrofina usando para isto vetor viral, é a forma que possibilitaria a produção de uma micro proteína, independente da alteração genética subjacente.

\section{Conclusão}

Embora no Brasil não exista aprovação de nenhuma destas novas propostas terapêuticas, temos perspectivas de no futuro próximo podermos modificar o curso de doenças progressivas. 


\section{AVANÇOS TERAPÊUTICOS NA AMIOTROFIA ESPINHAL}

THERAPEUTIC ADVANCES IN SPINAL MUSCULAR ATROPHY

Edmar Zanoteli

Médico e Professor Associado do Departamento de Neurologia da Faculdade de Medicina da Universidade de São Paulo

\section{RESUMO}

A amiotrofia espinhal (AME) é uma doença degenerativa hereditária dos neurônios motores inferiores associada com fraqueza muscular progressiva e atrofia muscular, e herança autossômica recessiva. A doença é classificada de acordo com a gravidade dos sintomas em tipo I (não senta), tipo II (sentam), tipo III (andam) e tipo IV (início na vida adulta). O gene SMN (sobrevida do neurônio motor) está presente em 2 cópias em cada cromossomo 5, designado SMN1 e SMN2. A maioria dos casos de AME é causada por deleção em homozigose do exon 7 do gene SMN1. Existe uma aproximada correlação inversa entre o número de cópias do gene SMN2 e a gravidade da doença. Não há cura para a AME até o momento, e o tratamento consiste em uma abordagem multidisciplinar. Diversas novas estratégias terapêuticas estão em andamento e incluem: a) terapia gênica para corrigir a mutação no $S M N 1$, b) neuroproteção, para reduzir a morte do neurônio motor, c) uso de células tronco, e d) ativação do gene SMN2 para aumentar a produção da proteína SMN funcional. Neste último caso, uma abordagem promissora inclui a inibição do ISS-N1 (Intronic Splicing Silencer N1) localizado próximo do exon 7 no gene SMN2, utilizando um oligonucleotideos, para reduzir a exclusão do exon 7 durante a transcrição do gene SMN2.

Palavras-chave. amiotrofia espinhal, sobrevida do neurônio motor, SMN, terapias 


\section{ABSTRACT}

Spinal muscular atrophy (SMA) is a hereditary degenerative disorder of lower motor neurons associated with progressive muscle weakness and atrophy and autosomal recessive inheritance. SMA subtypes are classified by severity of weakness in type I (non sitters), type II (sitters), type III (walkers), and type IV (adult-onset). The SMN (survival of motor neuron) gene is present in 2 copies on each chromosome 5, designated SMN1 and SMN2. A majority of cases of SMA are caused by homozygous deletions of exon 7 of the SMN1 gene. An approximate inverse correlation exists between SMN2 gene copy number and severity of disease. No cure exists for SMA, and the treatment consists of multidisciplinary approach. Many new therapeutic strategies are under way and includes: a) gene therapy to correct the SMN1 mutation, b) neuroprotection, to reduce the motor neuron death, c) stem cell approach, and d) activation of SMN2 gene to increase the production of functional SMN protein. In this last case, a promise approach includes an inhibition of the Intronic Splicing Silencer N1 (ISS-N1) located close to the exon 7 in SMN2 gene, using an oligonucleotide, to reduce the exclusion of exon 7 during the SMN2 transcription.

Keywords. spinal muscular atrophy, survival motor neuron, SMN, therapy 


\section{DESENVOLVIMENTO E ANÁLISE DE USABILIDADE DO TESTE DE ACUIDADE MOTORA DE PINÇA MANUAL EM ATIVIDADE GRÁFICA (TAG)}

Francisca Francineide Moreira Assalim ${ }^{1}$; Francis Meire Favero ${ }^{1,2}$; Mariana Callil Voos ${ }^{1,2,3}$; Fátima Aparecida Caromano ${ }^{3}$

${ }^{1}$ Universidade Federal de São Paulo

2Universidade Ibirapuera

${ }^{3}$ Universidade de São Paulo

\section{RESUMO}

Coordenação motora fina implica em adequada integração e funcionamento do sistema nervoso central, de forma a atingir respostas motoras precisas. Testes para analisar este tipo de resposta se fazem necessários. Desenvolver um teste manual gráfico e submeter à avaliação por peritos e usabilidade. As atividades-teste foram desenvolvidas no software Excel, e organizadas em nível fácil e complexo. Encaminhamento de teste com seu manual e questionário, em ficha de avaliação para os pareceristas em duas fases consecutivas. Testagem de usabilidade com 4 fisioterapeutas e 30 pacientes, denominado aplicação piloto. Verificada deficiência no manual e no teste, a partir de informes de estudo piloto e pareceristas, foram inseridas adequações e posteriormente foi reencaminhado aos pareceristas, que consideraram 0 teste satisfatório do ponto de vista técnico. Foi possível desenvolver um teste de coordenação motora fina, no formato de atividades gráficas, considerando pertinente pela maioria dos peritos, sendo este teste, simples, rápido e com custo módico, como pretendido pelos autores, a ser refinado futuramente, denominado inicialmente Teste de Acuidade Motora de Pinça Manual em Atividade Gráfica (TAG).

Palavras-chave. Mãos, Avaliação, Mulheres, Envelhecimento, Usabilidade 


\section{ANÁLISE DE CONFIABILIDADE INTRA-EXAMINADOR DO TESTE DE ACUIDADE MOTORA DE PINÇA MANUAL EM ATIVIDADE GRÁFICA (TAG)}

Nathanna Larissa Stefanin ${ }^{1}$; Francis Meire Favero ${ }^{1,2}$; Mariana Callil Voos $^{1,2,3}$; Fátima Aparecida Caromano ${ }^{3}$

${ }^{1}$ Universidade Federal de São Paulo

${ }^{2}$ Universidade Ibirapuera

${ }^{3}$ Universidade de São Paulo

\section{RESUMO}

A atividade motora fina é adquirida ao longo do desenvolvimento humano, a exemplo da destreza manual. A Fisioterapia contribui com as áreas de desenvolvimento e pesquisa que visam aprimorar as ferramentas de avaliação e condutas. Analisar a confiabilidade intraexaminador do teste TAG. Estudo quantitativo e descritivo que utilizou o teste TAG. Participaram 3 grupos de 30 pessoas saudáveis nas faixas etárias de 30, 60 e 70 anos, avaliadas por 2 examinadores treinados e os dados coletados por 2 coletores treinados, cegos aos estudos. Observamos entre os três grupos que, indivíduos com idade entre 30-39 anos obtiveram melhor desempenho nas avaliações, deve-se ressaltar, ser essa uma população economicamente ativa, e de grande importância na prática médica diária. Entre outros fatores, podemos explicar o menor desempenho nas idades entre 60-69 anos e 70-79 anos, sendo o menor deles na idade compreendida entre 7079 anos, devido as alterações sistêmicas ou locais, nos membros superiores e acentuam-se com a idade. A confiabilidade intraexaminador variou de moderada a excelente. O refinamento do teste por meio da submissão a pareceristas e aplicação em estudo piloto, tornou seus dados confiáveis quando coletados na situação intraexaminador. O estudo mostrou que o TAG apresenta confiabilidade intra avaliador variando de muito boa a excelente, desde que os examinadores sejam treinados, considerando as variáveis separadamente e em grupo, e considerando os grupos isoladamente ou na totalidade.

Palavras-chave. avaliação, idade, desenvolvimento, Confiabilidade, Envelhecimento 


\section{ANÁLISE DE CONFIABILIDADE INTEREXAMINADORES DO TESTE DE ACUIDADE MOTORA DE PINÇA MANUAL EM ATIVIDADE GRÁFICA (TAG)}

Ligiane Paula Silveira Lamunier ${ }^{1}$; Francis Meire Favero ${ }^{1,2}$; Mariana Callil Voos ${ }^{1,2,3}$; Fátima Aparecida Caromano ${ }^{3}$

1.Universidade Federal de São Paulo

2.Universidade Ibirapuera

3.Universidade de São Paulo

\section{RESUMO}

Poucos testes analisam acuidade motora da pinça manual, e destes, pouco se sabe sobre suas propriedades psicométricas. Análise da confiabilidade interexaminadores do TAG. Estudo quantitativo, prospectivo. Os materiais utilizados para realização do TAG foram: Folha quadriculada $(1 \mathrm{~cm} \times 1 \mathrm{~cm})$, com figuras impressas; lapiseira grafite 0,9mm; cadeira com encosto ajustável; mesa e cronômetro. Participaram 3 grupos de 30 pessoas saudáveis nas faixas etárias de 30, 60 e 70 anos, avaliadas por 2 examinadores treinados, cego ao estudo e os dados coletados por 2 coletores treinados, cegos aos estudos. A coleta teve intervalo de realização de uma semana. Em função do refinamento do teste por meio da submissão a pareceristas e aplicação em estudo piloto, foi possível coleta de dados padronizada. A confiabilidade do TAG variou de moderada a alta, para os dois níveis de dificuldade propostos pelo teste e, considerando as 3 variáveis analisadas, ou seja, número de traços total, número de traços corretos e porcentagem de acerto. $O$ estudo mostrou que 0 TAG apresenta confiabilidade entre avaliadores variando de muito boa a excelente, desde que estes sejam treinados, considerando as variáveis separadamente e em grupo, e considerando os grupos isoladamente ou na totalidade, sem variação em função do grupo etário.

Palavras-chave. treinamento, confiabilidade, avaliação, desenvolvimento, envelhecimento 


\section{ANÁLISE DO DESEMPENHO DE MULHERES NA FAIXA DE 60 A 69 ANOS NO TESTE DE ACUIDADE MOTORA DE PINÇA MANUAL EM ATIVIDADE GRÁFICA (TAG)}

Mayara de Oliveira Cotrim ${ }^{1}$; Francis Meire Favero ${ }^{1,2}$, Mariana Callil Voos $^{1,2,3}$; Fátima Aparecida Caromano 3

1.Universidade Federal de São Paulo

2.Universidade Ibirapuera

3.Universidade de São Paulo

\section{RESUMO}

O teste TAG, por ser novo, necessita ser aplicado em diferentes populações e situações para gerar parâmetros de comparação e para descrição do desempenho em diferentes faixas etárias. Descrever e comparar o desempenho de mulheres saudáveis, no teste TAG, com foco em mulheres de 60-69 anos. Estudo descritivo e comparativo. Participaram, 60 mulheres saudáveis com idade entre 60 e 69 (G1) no grupo experimental e 30 mulheres na faixa de 70-79 anos. Para ambos os grupos, foram critérios de inclusão a ausência de comprometimento neuromuscular, cardiopulmonar ou musculoesquelético e sem história de lesão em membro superior. As participantes executaram o teste seguindo as normas propostas pelos autores do teste. Foram analisadas as variáveis número de traços, porcentagem de traços corretos e número de traços corretos por meio de análise estatística descritiva. Existe diferença no número de traços, número de acertos e porcentagem de acertos produzidos pelos dois grupos ( $p=0,007,0,006$ e 0,001 respectivamente), sendo os valores do $\mathrm{G} 2$ superiores aos do G1. Os dois grupos apresentaram diferença estatisticamente significativa quanto ao nível de dificuldade das tarefas $n 1$ e $n 2$ ( $G 1$ com $p=0,03$ e $G 2$ com $p=0,004)$, sendo que, o número de traços, a porcentagem de acerto e o número de acertos foram inferiores para o grupo G1. O estudo mostrou as características de desempenho de dois grupos etários diferentes e concluiu que, a idade afeta o desempenho. A tarefa 2 (n2) se mostrou mais complexa que a tarefa $1(\mathrm{n} 1)$, como esperado.

Palavras-chave. Desempenho, tarefa, atividade, teste, análise, idade 


\section{ANÁLISE DO DESEMPENHO DE MULHERES IDOSAS (70-79 ANOS) NO TESTE DE ACUIDADE MOTORA DE PINÇA MANUAL EM ATIVIDADE GRÁFICA (TAG)}

Vanessa da Silva Nascimento ${ }^{1}$; Francis Meire Favero ${ }^{1,2}$; Mariana Callil $\operatorname{Voos}^{1,2,3}$; Fátima Aparecida Caromano 3

1.Universidade Federal de São Paulo

2.Universidade Ibirapuera

3.Universidade de São Paulo

\section{RESUMO}

O teste TAG foca destreza manual fina ou precisão. Necessita de valores de referência para diferentes populações, de tal forma a fornecer valores para comparação. Comparar o desempenho de dois grupos de mulheres saudáveis de faixa etárias diferentes, com foco em mulheres de 70-79 anos. Estudo experimental, prospectivo, descritivo e comparativo. Participaram do estudo, 60 mulheres saudáveis com idade entre 60 e 69 (G1) no grupo experimental e 30 mulheres na faixa de 70-79 anos. Para ambos os grupos, foram critérios de inclusão a ausência de comprometimento neuromuscular, cardiopulmonar ou musculoesquelético e sem história de lesão em membro superior. As participantes executaram o teste seguindo as normas propostas pelos autores do teste. Foram analisadas as variáveis número de traços, porcentagem de traços corretos e número de traços corretos por meio de análise estatística descritiva. O G1 não mostrou diferença estatisticamente significativa no desempenho quanto ao nível de dificuldade do teste, n1 e n2, quando considerada a porcentagem de acertos $(0,165)$. O G2 apresentou diferença estatisticamente significativa no desempenho quanto ao nível de dificuldade do teste, $\mathrm{n} 1$ e $\mathrm{n} 2$, quando considerada a porcentagem de acertos $(0,015)$. G1 fez um número médio de traços no $n 1$ de dificuldade estatisticamente maior que no $n 2(p=0,007)$, 0 que pode indicar mais calma e portanto, melhor desempenho no nível 2 de dificuldade $(p=0,421)$, podendo este fato ser relacionado com estratégia do grupo e não desempenho. Foi possível descrever o desempenho da população estudada no teste TAG.

Palavras-chave. desempenho, avaliação, idade, análise, atividade 


\section{RELAÇÃO ENTRE O CONTROLE DE TRONCO (SATCO), A FUNCIONALIDADE E A FUNÇÃO DE MOTORA DISTAL (MFM-D3) DE PACIENTE COM DISTROFIA MUSCULAR DE DUCHENNE}

Elaine Figueredo de Sousa ${ }^{1}$ Ana Lúcia Yaeko da Silva Santos ${ }^{1}$; Francis Meire Favero ${ }^{1}$; Luis Fernando Grossklauss ${ }^{1}$; Acary Souza Bulle Oliveira ${ }^{1}$; Cristina dos Santos Cardoso Sá ${ }^{2}$.

1 Universidade Federal de São Paulo, Departamento de Neurologia/Neurocirurgia, São Paulo SP, Brasil;

${ }^{2}$ Universidade Federal de São Paulo, Departamento Ciências do Movimento Humano, São Paulo SP, Brasil.

\section{RESUMO}

A distrofia muscular de Duchenne (DMD) tratar-se de uma doença degenerativa e progressiva, caracterizada por comprometimento motor com perda do equilíbrio, controle de tronco, e redução das funcionalidades tanto dos membros inferiores (MMII) quanto dos membros superiores (MMSS). Objetivo: Verificar a relação entre 0 controle de tronco, a funcionalidade e a função do membro superior em pacientes com DMD. Método: Este estudo foi aprovado pelo comitê de ética da Universidade Federal de São Paulo (CEP: 1.367.911). Doze pacientes com diagnóstico de DMD foram submetidos a avaliação quanto aos aspectos motores pela Escala Vignos, Segmental Assessment of Trunk Control (SATCo) e Medida de Função Motora Distal D3 (MFM). O teste Kolmogorov Smirnov verificou a normalidade dos dados. Posteriormente, foi realizado o teste de correlação por meio do teste de Pearson. Resultados: Doze pacientes com média de idade 10,5 $\pm 2,71$ anos, escore Vignos de $3,8 \pm 2,29$. Nível de controle lombar inferior $(6,4 \pm 1,73)$, e escore D3 de 19,2 $\pm 2,26$ demonstra boa função motora distal. Houve correlação forte entre controle de tronco e função motora distal, estatisticamente significativa $(r=0,761 ; p=0,004)$ e correlação moderada entre controle de tronco e escore de funcionalidade sem significância estatística $(r=-0,509 ; p=0,091)$. Conclusão: $O$ estudo demonstra a relação entre o controle de tronco, a função de MMSS e o nível funcional de pacientes com DMD e sugere a inclusão de estimulação do controle de tronco para o melhor desempenha na execução de tarefas funcionais.

Palavras-chave. Distrofia Muscular de Duchenne; Postura; Extremidade Superior, função, controle. 


\section{AVALIAÇÃO DO CONTROLE DE TRONCO E FUNÇÃO RESPIRATÓRIA EM PACIENTES COM DISTROFIA MUSCULAR DE DUCHENNE}

Bruna de Souza Freitas ${ }^{1}$; Francis Meire Fávero ${ }^{1}$, Cristina dos Santos Cardoso de Sá ${ }^{2}$

1 Departamento de Neurologia Clínica - Setor de Doenças Neuromusculares - Universidade Federal de São Paulo

2 Departamento de Ciências do movimento humano - Universidade Federal de São Paulo.

\section{RESUMO}

A progressão da fraqueza muscular reduz a independência funcional desta população, afetando sua qualidade de vida. Estudos prévios apontam que o controle de tronco é essencial para realização de atividades de vida diária bem como para uma boa função respiratória. Avaliar o controle de tronco e o desempenho da avaliação respiratória de pacientes com DMD. Treze pacientes com diagnóstico de Distrofia muscular de Duchenne (DMD) foram submetidos à avaliação quanto ao aspecto cognitivo pelo Mini Exame do Estado Mental, aspectos motores pela Escala Vignos, Segmental Assessment of Trunk Control (SATCo) e aspectos respiratórios pela Espirometria, Manovacuometria e Medida de Fluxo Expiratório. O nível 1 de controle de tronco foi o mais prevalente entre pacientes $(53,8 \%)$; a maioria dos pacientes apresentaram Vignos 7 (61,5\%); os valores espirométricos e do Peak Flow Meter estão dentro dos valores de normalidade para esta população, entretanto os valores das pressões máximas estão comprometidos. A análise estatística mostra correlação moderada entre a SATCo $x$ Espirometria (\%), correlação forte entre a SATCo $x$ PEmáx e correlação muito forte entre SATCo x Escala Vignos. Há relação entre o controle de tronco, o nível funcional e função respiratória de pacientes com DMD. Apesar da maioria dos pacientes apresentarem comprometimento importante de tronco, a função respiratória através da espirometria mantém-se estável, porém com as pressões máximas estão em um nível importante de declínio. Palavras-chave. Distrofia Muscular de Duchenne, Escala Vignos, Segmental Assessment of Trunk Control, Função respiratória. 


\section{CORRELAÇÃO ENTRE AS ESCALAS FUNCIONAIS EM PACIENTES COM DIAGNÓSTICO DE ESCLEROSE LATERAL AMIOTRÓFICA}

Carina Vitorino de Medeiros $^{1}$, Cristina dos Santos Cardoso de Sá ${ }^{2}$, Francis Meire Fávero ${ }^{1}$

1 Departamento de Neurologia Clínica - Setor de Doenças Neuromusculares - Universidade Federal de São Paulo

2 Departamento de Ciências do movimento humano - Universidade Federal de São Paulo.

\section{RESUMO}

O estudo analisou a correlação entre instrumentos de avaliação funcional validado e não validado para pacientes com diagnóstico de Esclerose Lateral Amiotrófica. Foram incluídos 33 pacientes com ELA que apresentavam a marcha selecionados no Setor de Investigação de Doenças Neuromusculares da Universidade Federal de São Paulo/Escola Paulista de Medicina, submetidos Mini Exame do Estado Mental afim de verificar o grau de compreensão, escala de Vignos, Amyotrophic Lateral Sclerosis Functional Rating Scale - Revised (ALSFRS-R), a Medida da Função Motora (MFM), e a Força Muscular (FM) $(M R C \%)$, para análise foi utilizado testes de correlação de Pearson (dados paramétricos) e/ou Spearman (dados nãoparamétricos), considerando coeficientes fortes de $(r>0,70)$ ou moderados $(0,40<r>0,70)$. Correlações entre as escalas funcionais e também a força muscular (MRC\%), a ALSFRS versus MFM-D2 $(r=0,43)$, ALSFRS versus MFM-D3 $(r=0,59)$, ALSFRS versus força muscular proximal de MMSS $(r=0,54)$, ALSFRS versus FM Distal de MMSS $(r=0,63)$, ALSFRS versus Vignos $(r=0,43)$, FM Proximal de MMII versus MFM-D1 $(r=0,72)$, FM Distal de MMII versus MFM-D1 $(r=0,82)$, FM Proximal de MMSS versus MFM-D2 $(r=0,53)$, FM distal de MMSS versus MFM-D2 $(r=0,54)$ FM Proximal de MMSS versus MFM-D3 $(r=0,73)$, FM Distal de MMSS versus MFM-D3 $(r=0,67)$, FM Proximal de MMII versus Vignos $(r=0,54)$ FM distal de MMII versus Vignos $(r=0,57)$, Vignos versus MFM-D1 $(r=0,57)$. Conclui-se que as escalas de avaliação funcional são fundamentais para compreensão do quadro clínico e acompanhar a evolução clínica de indivíduos com 
ELA. Foi possível demonstrar correlação entre as escalas funcionais ALSFRS, Vignos, Medida da função Motora e suas dimensões com a força muscular dos segmentos distais e proximais de MMSS e MMII de pacientes com ELA. Houve correlação positiva entre Escala de Vignos e Dimensão 1 da medida de função motora.

Palavras-chave. escalas, função, Esclerose Lateral Amiotrófica, avaliação. 


\section{ANÁLISE DAS ESCALAS COGNITIVAS EM PACIENTES COM DIAGNÓSTICO DE ESCLEROSE LATERAL AMIOTRÓFICA}

Luana Cautella da Costa Figo ${ }^{1}$, Cristina dos Santos Cardoso de Sá ${ }^{2}$, Francis Meire Fávero ${ }^{1}$

1 Departamento de Neurologia Clínica - Setor de Doenças Neuromusculares - Universidade Federal de São Paulo

2 Departamento de Ciências do movimento humano - Universidade Federal de São Paulo.

\section{RESUMO}

O estudo analisou a correlação entre instrumentos de avaliação motora e cognitiva validado, sendo estes realizados em pacientes com diagnóstico de Esclerose Lateral Amiotrófica. Avaliar as alterações cognitivas de um grupo de pacientes em diferentes estágios de DNM/ELA. Estudo prospectivo observacional transveral, foram aplicados testes que avaliam as habilidades cognitivas em 21 pacientes com diagnóstico definido de Esclerose Lateral Amiotrófica, apresentando autonomia nos MMSS e fala normal. Utilizado MiniExame do Estado Mental, teste de fluência verbal (animais, letra P e letra S), ordem dos dígitos (ordem direta e inversa) e o teste do relógio correlacionando também com escala de Vignos, Amyotrophic Lateral Sclerosis Functional Rating Scale - Revised (ALSFRS-R) e a Medida da Função Motora (MFM), para análise foi utilizado testes de correlação de Pearson (dados paramétricos) e/ou Spearman (dados não-paramétricos), considerando coeficientes fortes de $(r>0,70)$ ou moderados $(0,40<r>0,70)$. Pacientes selecionados no Setor de Investigação de Doenças Neuromusculares da Universidade Federal de São Paulo/Escola Paulista de Medicina e na residência dos mesmos, em Campinas. Foram apresentados na análise de estatística forte correlação entre as variáveis cognitivas sendo TR com animais e letra $\mathrm{P}$, Animais com TR- letra P- letra S- Ordem Direta, Ordem Inversa com letra P- letra S, letra S com letra P- animais- ODI, correlacionando também com escalas funcionais TR com a Vignos e ALSFRS, letra S com D3- MFM total- ALSFRS, letra P com ALSFRS. Pode-se concluir que as escalas de avaliação cognitiva são fundamentais para compreensão do quadro e acompanhamento da evolução clínica de pacientes com ELA. Também que existe uma correlação das alterações cognitivas com a progressão do comprometimento motor.

Palavras-chave. escalas, cognitivo, Esclerose Lateral Amiotrófica, avaliação 


\section{USABILIDADE DA TECNOLOGIA EYE TRACKING PARA COMUNICAÇÃO AUMENTATIVA}

Letícia Simões Ferreira ${ }^{1}$, Vagner Rogério dos Santos², Abrahão Augusto Juviniano Quadros ${ }^{3}$

1 - Especializanda do Curso de Intervenção Fisioterapêutica nas doenças Neuromusculares da Universidade Federal de São Paulo UNIFESP

2 - Doutor pela Universidade Federal de São Paulo - UNIFESP

3 - Coordenador do Ambulatório de Síndrome Pós-Poliomielite da Universidade Federal de São Paulo - UNIFESP

\section{RESUMO}

O Eye Tracking refere-se a um conjunto de tecnologias que mensuram e registram os movimentos oculares do indivíduo perante a amostragem de um estímulo. Na computação, a usabilidade abrange tanto a facilidade como a simplicidade com que determinada interface ou aparelho, pode ser utilizado. Podendo até ser aplicada em ergonomia fazendo referência a design de objetos cotidianos. Portanto, uma avaliação é essencial para identificar as necessidades do usuário, problemas de interação e interferências da interface no momento do uso. Avaliar a Tecnologia Eye Tracking na construção de um protocolo de avaliação da usabilidade. Baseada em testes gravados divididos em etapas, com tempos determinados, que abrangiam o recebimento, conexão dos itens, instalação e configuração dos softwares e realização de uma tarefa específica utilizando o comando visual. A maioria dos participantes encontraram dificuldades no posicionamento e calibração do software Primma e no idioma pré-configurado; houve desistência em 20\% dos testes por fadiga. O protocolo desenvolvido foi capaz de avaliar a usabilidade pré-uso do dispositivo e que o fisioterapeuta pode fornecer feedbacks importantes para avaliar uma tecnologia, podendo esta ser assistiva.

Palavras-chave. Comunicação, Comportamento do Consumidor, Equipamentos de Auto-ajuda. 


\section{AVALIAÇÃO DE APRENDIZAGEM MOTORA POR MEIO DE TAREFA EM REALIDADE VIRTUAL EM INDIVÍDUOS COM DISTROFIA MUSCULAR DE DUCHENNE}

Karina Silva de Oliveira ${ }^{1}$, Talita Dias², Fátima Aparecida Caromano ${ }^{2}$ 1. Especializanda da Universidade Federal de São Paulo

2. Universidade de São Paulo

\section{RESUMO}

A distrofia muscular de Duchenne é uma das doenças genéticas mais comuns e mais grave das distrofias musculares. Essa alteração genética resulta na ausência da produção de distrofina. Os jogos de reabilitação baseado em tarefas cotidianas têm sido sugeridos para facilitar a reabilitação física contínua em casa. A realidade Virtual é uma técnica avançada de interface homem e máquina, onde o usuário pode imergir e interagir em um ambiente sintético tridimensional gerado por computador. O objetivo deste estudo é verificar se dispositivos de interação mais abstratos (sem toque físico - mais virtual) permitem melhora de desempenho na tarefa, quando comparados com dispositivos mais concretos (com toque físico). Trata-se de um estudo transversal do tipo observacional. Esse projeto avaliou 40 pessoas do sexo masculino com idade entre 11 e 29 anos escolhidos aleatoriamente, com diagnóstico médico de DMD. Resultados: No que diz respeito à transferência para uma velocidade mais elevado resultado do presente estudo indica que eles levaram menos tempo para realizar a tarefa, $(M=234 \mathrm{~ms})$ para a transferência $(M=177 \mathrm{~ms})$. A tarefa na interface virtual promoveu uma ótima transferência do desempenho e durante a fase de transferência com aumento de velocidade da tarefa os valores foram similares. Conclusão: Assim, conclui-se que a tarefa virtual parece ser mais difícil para pessoas com DMD, entretanto a prática neste tipo de interface parece gerar diferentes engramas motores, que auxiliam na transferência da habilidade motora com um aumento significante de desempenho.

Palavras-chave. Distrofia Muscular, Duchenne, Aprendizagem motora, Timing coincidente, Realidade Virtual. 


\section{INSTRUMENTOS DE AVALIAÇÃO DA DOR EM INDIVÍDUOS COM DISTROFIA MUSCULAR DE DUCHENNE - UMA REVISÃO DE LITERATURA}

Nelma Silva dos Santos ${ }^{1}$, Thais Massetti ${ }^{2}$, Francis Meire Favero ${ }^{3}$ 1.Especializanda da Universidade Federal de São Paulo

2.Universidade de São Paulo

3. Professora Afiliada da Universidade Federal de São Paulo

\section{RESUMO}

Distrofia Muscular de Duchenne (DMD) é uma das formas mais comuns e severas das distrofias sendo definida como uma doença de herança recessiva, ligada ao cromossomo $X$, causada por mutações patogênicas no gene distrofina, levando à total ou anormal ausência da distrofina. O desenvolvimento motor de meninos com DMD, é marcado por um período inicial de ganho de habilidades motoras, porém com a evolução da doença ocorre um declínio de força muscular e função motora, posteriormente a perda da marcha. Historicamente, a dor não tem sido considerada como uma parte importante do sintoma de manifestação da doença neuromuscular (NMD). Investigar a relação entre DMD e dor, por meio de uma revisão de literatura. Foi realizada uma revisão da literatura nas bases MedLine/PubMed e BVS (Biblioteca Virtual em Saúde), por meio dos descritores. "Duchenne Muscular Dystrophy" e "Pain", foram utilizados os artigos publicados disponíveis até junho de 2015. Nos trabalhos analisados nesta revisão, a dor é um problema comum e frequente em indivíduos com Distrofia Muscular de Duchenne. Analisaram a dor em vários aspectos: sintomas, intensidade, frequência, duração, local, interferência e agravantes, o impacto da dor. Os instrumentos utilizados foram: Escala Visual Analógica (EVA), Inventário Breve de Dor (IBD). Todos os oito estudos continham diferentes participantes e tamanho de amostra. A maior população foi 862 pacientes e a menor população 7 pacientes com Distrofia Muscular de Duchenne. A partir da análise dos artigos estudados, os quais revelaram uma dificuldade importante e extremamente relevante para qualificar os tipos de estudos. Concluímos que a dor é um problema frequente na população, sendo esse sintoma potencialmente tratável. A avaliação desse sintoma deve ser padrão no atendimento desta população.

Palavra-chaves. Dor, Distrofia Muscular de Duchenne, avaliação, escalas 


\section{EFEITOS DA TERAPIA POR CONTENSÃO INDUZIDA MODIFICADA EM PACIENTES COM ACIDENTE VASCULAR \\ CEREBRAL}

Francisca Antônia Almeida de Carvalho Guerreiro1, Rafael Eras Garcia $^{2}$, Francis Meire Favero ${ }^{3}$

1.Especializanda do Curso de Neurologia Clínica Universidade Federal de São Paulo - UNIFESP

2.Mestrando pelo Programa de Pós-Graduação em Terapia Ocupacional (PPGTO/UFSCar)

3.Professora Afiliada do Departamento de Neurologia e Neurocirurgia da Universidade Federal de São Paulo - UNIFESP

\section{RESUMO}

O acidente vascular cerebral é considerado uma perda súbita da função neurológica, sendo a paresia do membro superior um dos comprometimentos motores mais comuns após este tipo de lesão. Frente a diversas tentativas frustradas em utilizar o membro superior mais afetado, o paciente prefere usar o membro não afetado em suas atividades, desenvolvendo o não uso aprendido deste membro. Para tratar este fenômeno, foi desenvolvida na Universidade do Alabama em Birmingham, a Terapia de Contensão Induzida (TCI), método de tratamento intensivo de reabilitação do membro superior. Contudo, o protocolo mais utilizado consiste em 3 horas de terapias diárias, por 10 dias consecutivos, desafio importante para a realidade brasileira, que conta com tempo e recursos escassos. Investigar os efeito terapia de contensão induzida modificada em pacientes com acidente vascular cerebral. Estudo experimental, de caráter quantitativo, randomizado controlado. O protocolo modificado mostrou-se eficaz para a reversão do não uso imediatamente após a intervenção, associada ao aumento significativo na qualidade, quantidade, velocidade e força da função motora do membro superior afetado. 0 protocolo modificado da TCI demonstra potencial para a reabilitação dos membros superiores, pelo reduzido tempo na execução das atividades, maximizando os resultados.

Palavras-chave. Realidade virtual, Acidente Vascular Cerebral, desenvolvimento 


\section{ANÁLISE DO PERFIL DE PROCESSAMENTO SENSORIAL DE CRIANÇAS COM TRANSTORNO DO ESPECTRO AUTISTA E SEUS \\ PAIS}

Raquel Kaori Nagai ${ }^{1}$, Ana Luiza Console Andreotti ${ }^{2}$

1. Especializanda do Curso de Neurologia Clínica Universidade Federal de São Paulo - UNIFESP

2.Doutora pela Universidade de São Paulo - USP

\section{RESUMO}

Sintomas de reatividade sensorial (como hiper ou hiporreatividade) ou interesse incomum por aspectos sensoriais do ambiente foram acrescidos como critérios diagnósticos da pessoa com Transtorno do Espectro Autista (TEA), no DSM-V (2013). O presente estudo tem como objetivo analisar e correlacionar possíveis variáveis e padrões do processamento sensorial de pais e crianças com TEA, baseado nos resultados do Perfil Sensorial, em suas versões infantil (PS - Dunn, 1999) e adolescente/adulto (PSAA - Dunn, 2002). Foram analisados os padrões de resposta sensoriais de 9 participantes no grupo de crianças com TEA e de 9 pais deste respectivo grupo. Os resultados obtidos indicam que não foi possível constatar concordância entre os escores do PS e PSAA analisados, contudo pode-se notar déficits no processamento sensorial tanto de crianças com autismo quanto de seus pais. Os resultados deste estudo foram limitados devido ao tamanho da amostra e a heterogeneidade na participação de pais ( 9 mães e somente 3 pais participaram do estudo). Apesar disto, podemos considerar os resultados deste estudo relevantes, pois considerando que existem alterações no processamento sensorial de ambos os grupos estudados, os impactos destes déficits podem causar grandes limitações em seus respectivos cotidianos.

Palavras-chave. Autismo; Processamento Sensorial; Perfil sensorial. 


\section{ANÁLISE DO DESEMPENHO FUNCIONAL DE PACIENTES HEMIPARÉTICOS APÓS APLICAÇÃO DE BLOQUEIO QUÍMICO}

Marília Luna Pereira1, Fernando Morgadinho Santos Coelho², Francis Meire Favero ${ }^{3}$

1. Especializanda do Curso de Neurologia Clínica Universidade Federal de São Paulo - UNIFESP

2.Professor do Departamento de Neurologia e Neurocirurgia da Universidade Federal de São Paulo - UNIFESP

3.Professora Afiliada do Departamento de Neurologia e Neurocirurgia da Universidade Federal de São Paulo - UNIFESP

\section{RESUMO}

Analisar o desempenho funcional dos pacientes hemiparéticos após o bloqueio químico (BQ). Foram tratados 2 pacientes com diagnóstico de acidente vascular cerebral isquêmico (AVCI), tendo como sequela a hemiparesia à $D$, tempo médio de lesão de 8 anos, ambos os sexos e média de idade de 47 anos (44-50). Os 2 passaram por avaliação no início do tratamento, onde foram coletadas medidas de força e amplitude articular do membro superior direito (MSD), feito BQ e após 1 semana, iniciado tratamento com a fisioterapia convencional (FC) associado ao uso do treino direcionado à tarefa (Shaping), recurso da Terapia por Contensão Induzida (TCI); após 2 e 3 meses, reavaliados com os mesmos instrumentos usados, o dinamômetro hidráulico JAMAR e o Goniômetro universal. O atendimento desses pacientes teve duração de 3 horas/dia, 5 dias/semana por um período de 6 meses. Os pacientes tratados com as duas terapias (Shaping + FC), após o BQ, apresentaram evolução significativa na melhora da força muscular e amplitude de movimento do membro superior (MS), principalmente na extensão de punho, cotovelo e abdução do ombro. A FC associada ao Shaping após o bloqueio químico, exercem um papel preponderante para a recuperação do MS no paciente hemiparético.

Palavras-chave. Acidente Vascular Cerebral; Bloqueio Químico; Shaping; Fisioterapia. 


\section{PERFIL E DESENVOLVIMENTO DE CRIANÇA COM SÍNDROME DE PALLISTER-KILLIAN EM TRATAMENTO FISIOTERAPÊUTICO: RELATO DE CASO}

Ana Paula Bernardino ${ }^{1}$, Mariana D 'Angelo Cauchioli2

1.Especializanda do Curso de Neurologia Clínica Universidade Federal de São Paulo - UNIFESP

2.Especialista do Curso de Intervenção Fisioterapêutica nas doenças Neuromusculares - UNIFESP

\section{RESUMO}

A Síndrome de Pallister Killian (SPK) é uma patologia extremamente rara, desencadeada por tetrassomia do cromossomo 12 p. A manifestação desta síndrome ocorre de maneira distinta, mas existem algumas características mais frequentes. São elas: hipotonia, aparência facial grosseira, anomalias cutâneas pigmentares, alterações esqueléticas, atraso no desenvolvimento neuropsicomotor (ADNPM) e convulsões. Não existe um tratamento definitivo para a SPK, existem apenas tratamento multidisciplinar focado na reabilitação e na melhoria de qualidade de vida do indivíduo portador da doença. O objetivo deste trabalho é estudar as principais características clínicas e motoras apresentadas por uma paciente portadora da SPK, além de citar como a abordagem da fisioterapia pode contribuir para minimizar as limitações causadas pela doença, visando melhora do desempenho funcional direcionado ao caso. A criança com diagnóstico de SPK, realiza tratamento de fisioterapia na Clínica Cauchioli. As informações a respeito da paciente foram obtidas por meio de análise de prontuário e entrevista com o responsável. Foi realizada também pesquisa bibliográfica a respeito do tema. Ao final desta pesquisa concluiu-se que os fenótipos são variáveis, existe a possibilidade de diagnóstico precoce, porém os estudos a respeito da reabilitação na SPK ainda são muito escassos, mas que a fisioterapia tem um papel importante na melhoria das funções, bem como na qualidade de vida dos pacientes.

Palavras-chaves. Desenvolvimento, Criança, Tratamento, qualidade de vida 


\section{NEUROMODULAÇÃO E NOVAS PERSPECTIVAS PARA REABILITAÇÃO}

Poliana Tange Santos ${ }^{1}$, Thais Tavares Terranova ${ }^{2}$, Fabricio Ferreira de Oliveira ${ }^{3}$, Fernando Morgadinho Santos Coelho ${ }^{4}$

1. Especializanda do Curso de Neurologia Clínica Universidade Federal de São Paulo - UNIFESP

2.Fisioterapeuta da Rede de Reabilitação Lucy Montoro

3.Professor Afiliado do Departamento de Neurologia e Neurocirurgia UNIFESP

4.Professor Adjunto do Departamento de Neurologia e Neurocirurgia da Universidade Federal

\section{RESUMO}

Os déficits motores e cognitivos são sequelas comuns devido a danos cerebrais causados por diferentes patologias. As técnicas de neuromodulação não-invasiva têm sido cada vez mais utilizadas na reabilitação física e cognitiva de pacientes com sequelas de Acidente Cerebrovascular, como em pacientes com dor de membro fantasma. A metodologia adotada foi a revisão sistemática bibliográfica integrativa, através da qual foram pesquisadas evidências científicas, que serão sintetizadas e analisadas criticamente aqui. No final desta pesquisa, pode-se concluir que a Estimulação Elétrica por Corrente Contínua tem alguma eficácia comprovada tanto na reabilitação de pacientes com AVC como na redução da Dor do Membro Fantasma, porém é importante ressaltar a necessidade de novos estudos na área, visando a definição de protocolos.

Palavras-chave. Neuromodulação, Reabilitação, Transcranial Direct Current Stimulation, Estimulação Elétrica Transcraniana. 


\section{IMPLEMENTAÇÃO DO CUIDADO DE ENFERMAGEM AO CLIENTE ACOMETIDO COM TRAUMA RAQUIMEDULAR NA FASE AGUDA E PROPOSTA DE UM PROTOCOLO.}

Gabriela Ramos Gomes dos Santos ${ }^{1}$, Ana Paula Guarnieri ${ }^{2}$

1.Especializanda do Curso de Neurologia Clínica Universidade Federal de São Paulo - UNIFESP

2.Doutora em Enfermagem pela Universidade Federal de São Paulo UNIFESP

\section{RESUMO}

O cliente acometido com TRM necessita de um SAE personalizado, uma vez que a gravidade e a cronicidade do caso dependem disto para diminuição de agravos. O presente estudo descreve, se embasando em bases de dados de referência, o cuidado de Enfermagem ao cliente acometido com TRM, levando em conta sua segurança e cuidados profiláticos no que dizem respeito à diminuição de agravos futuros. Para o estudo em questão, optou-se pelo Pensamento Complexo de Avedis Donabedian que acredita que o cuidado deve ser sempre reavaliado, somado à Temática subjetividade do ser humano defendida por Myra Levine, que propõe uma visão holística do ser humano, unindo saúde, cliente e ambiente. Como conclusão deste trabalho, ficou claro que não possuímos um leque extenso de literatura acerca do tema, dentre os artigos analisados, apenas um tratava indiretamente desta discussão; e isso retrata que o cliente acometido por TRM recebe o mesmo padrão de prescrição que os demais internados na UTI, porém ficou mais que corroborado que estes indivíduos precisam de uma SAE personalizada, levando-se em conta a complexidade do caso e o ganho com medidas profiláticas.

Palavras chaves. TRM, SAE, Enfermagem, Profilaxia, Qualidade de Vida 


\section{PROTOCOLO PARA AVALIAÇÃO INTERDISCIPLINAR DA DIADOCOCINESIA}

Jéssica Talita da Cruz Albuquerque ${ }^{1}$; Christiane Brunini2; Mariana Callil Voos ${ }^{3}$.

1 Universidade Federal de São Paulo, Departamento de Neurologia/Neurocirurgia, São Paulo SP, Brasil;

${ }^{2}$ Coordenadora do Curso de Graduação da Universidade Ibirapuera, Doutoranda da Universidade Federal de São Paulo, São Paulo SP, Brasil;

3Universidade de São Paulo, Departamento Fonoaudiologia, Fisioterapia e Terapia Ocupacional, São Paulo SP, Brasil.

\section{RESUMO}

Diadococinesia é a capacidade de executar movimentos rápidos, repetidos ou alternados. Testes de diadococinesia podem avaliar tanto a fala quanto os membros superiores. O objetivo primário foi apresentar dados normativos para um protocolo interdisciplinar de avaliação da diadococinesia. Os objetivos secundários foram comparar o desempenho com os diferentes fonemas do teste de diadococinesia oral (PAPAPA, TATATA, KAKAKA e PATAKA), comparar o desempenho com as diferentes condições do teste de diadococinesia de membros superiores (realizado com ambos os membros superiores de forma espelhada, apenas com o membro superior direito, apenas com o membro superior esquerdo, com ambos os membros superiores de forma alternada) e investigar possíveis relações entre diadococinesia oral e de membros superiores. Participaram quinze adultos/ idosos saudáveis de 40 a 70 anos. Os dados foram representados por estatística descritiva. Os números de sílabas nas condições PAPAPA, TATATA, KAKAKA e PATAKA e os números de movimentos nas condições espelhado, direito, esquerdo e alternado foram comparados por ANOVA e correlacionados pelo teste de Pearson. Não houve diferença significativa entre os fonemas do teste de diadococinesia oral $(p<0,001)$. Houve diferença entre as condições avaliadas no teste de diadococinesia dos membros superiores $(p<0,001)$. O número de fonemas repetidos esteve correlacionado com 0 desempenho alternado de membros superiores. A correlação entre os escores dos testes de diadococinesia oral e de membros superiores pode ser explicada pelo fato da programação motora e da linguagem estarem predominantemente representadas no hemisfério esquerdo. Áreas cerebrais comuns/ adjacentes ou programas motores em comum podem nortear essas tarefas.

Palavras-Chaves. Parkinson, Protocolo, Avaliação, Interdisciplinar, Diadococinesia 


\section{APLICAÇÃO DA TERAPIA DE CONTENSÃO INDUZIDA (TCI) ADAPTADA NO AMBIENTE VIRTUAL EM PACIENTES COM ACIDENTE VASCULAR CEREBRAL}

Willian Severino da Silva1, Talita Dias², Francis Meire Favero ${ }^{3}$, Rafael Eras Garcia ${ }^{4}$

1.Especializando do Curso de Neurologia Clínica Universidade Federal de São Paulo - UNIFESP

2.Doutora em Ciências pela Universidade Federal de São Paulo UNIFESP

3.Professora Afiliada do Departamento de Neurologia e Neurocirurgia da Universidade Federal de São Paulo - UNIFESP

4.Mestrando pelo Programa de Pós-Graduação em Terapia Ocupacional (PPGTO/UFSCar)

\section{RESUMO}

Um Acidente Vascular Cerebral (AVC) é considerado uma perda súbita da função neurológica, pode levar a perda de diversas funções motoras e cognitivas, porém a sua recuperação depende da plasticidade neuronal que é caracterizada por alterações morfológicas ou funcionais de acordo com o estímulo utilizado. Assim, a Terapia de Contenção Induzida (TCI) tem sido discutida como uma das técnicas terapêuticas que apresentam resultados surpreendentes, porém com algumas limitações, por exemplo, espaço e carga. No entanto, a realidade virtual proporciona a execução dessas atividades oferecendo adaptações e proporcionando ao paciente a realização dessas tarefas funcionais com maior facilidade. Analisar 0 desempenho funcional da terapia de contensão induzida em ambiente virtual em pacientes com Acidente Vascular Cerebral. Todos os pacientes selecionados seguiram o protocolo da TCI, mas somente executaram 4 Shaping (colocar blocos em cima da caixa; limpar a mesa; colocando palitos em uma garrafa; feijão e colher). Duas atividades em cada sessão foram realizadas, com duração de 20 minutos cada, totalizando 1 hora de atendimento levando em consideração a correção do diário de casa e aplicação da moving activity log (MAL) (primeiros 15 itens em uma sessão e os 15 últimos itens), ao longo de 10 sessões. O grupo envolvido na pesquisa foi composto por 7 pacientes que realizaram a TCI adaptada em 
ambiente virtual. A análise estatística será realizada por forma descritiva, analisando médias e medianas. Dois pacientes conseguiram finalizar o protocolo de coleta até o momento, os mesmos apresentaram melhoras discretas na escala Fugl-Meyer nos itens ombro/cotovelo/punho e apenas punho, assim como houve tendência de aumento nas escalas WMFT e Mini Mental, enquanto na Orpington a tendência foi de diminuição da pontuação, em relação ao tempo a atividade de feijão e colher apresentou padrão decrescente e nas outras atividades crescentes. A TCI em realidade virtual obteve dados positivos, mas não significativos, carecendo de mais estudos relacionados.

Palavras-Chaves. Acidente cérebro vascular; Terapia por contenção induzida; Interface usuário-computador. 